\title{
Study on the Dynamic Relationship between Carbon Emissions and Energy Consumption in China
}

\author{
Yifeng Wang \\ School of Economics, Xiamen University, Xiamen, 361005, China
}

\begin{abstract}
Environmental issues have become increasingly prominent in China. Studying on the relationship between carbon emissions and energy consumption can help us to realize the target of reducing carbon emissions in 2020 . The article studies the dynamic relationship between carbon emissions and energy consumption. Using regression model initially judges the linear relationship between carbon emissions and energy consumption. Then the elasticity coefficient between carbon emissions and energy consumption is constructed. Using multivariate stochastic volatility model to study the dynamic relationship between carbon emissions and energy consumption. Using the regression model to investigate the prediction ability for the correlation coefficient. The result show that, there is a strong correlation between carbon emissions and energy consumption, and the time-varying correlation coefficient has a certain predictive ability on carbon emissions--energy consumption elasticity coefficient.

Keywords-carbon emissions; carbon emissions-energy consumption elasticity; MSV.
\end{abstract}

\section{INTRODUCTION}

With the rapid development in China, environmental problems are becoming more and more prominent, especially in recent years, air quality is getting worse. In all the problems, the issue of carbon emissions have been discussed wildly between scholars. In September 2009, the Chinese government announced the plans to reduce greenhouse gas emissions at the UN climate change conference which was held in Copenhagen. Our government propose that Chinese cut its greenhouse gas emissions by 40\% to 50\% below 2005 levels by 2020. Many studies showed that there is a strong correlation between carbon emissions and energy consumption, so this paper focuses on the dynamic relationship between carbon emissions and energy consumption.

By reading existing literature we found scholars generally believe that there is a positive correlation between carbon emissions and energy consumption. However, as we can see, the existing research about carbon emissions and energy consumption is static analysis, almost no articles discuss the dynamic correlation between them. So this paper focus on the dynamic correlation between the carbon emissions and energy consumption and its prediction ability.

The main work can be divided into four parts: (1) studying the linear relationship between carbon emissions and energy consumption by using the regression analysis; (2) using the data of carbon emissions and energy consumption to calculate the annual carbon emissions--energy consumption elasticity; (3) using DC-MSV model to extract the dynamic correlation coefficient between the carbon emissions and energy consumption; (4) investigating the prediction ability of time-varying correlation coefficient on the carbon emissions--energy consumption elasticity coefficient.

The subsequent sections of the article is as follows: The second part introduces the research method of this paper, mainly introduces the theoretical models, the third part is the empirical analysis, and the fourth part is the conclusion.

\section{RESEARCH METHODS}

\section{A. Carbon emissions -- energy consumption elasticity}

This paper attempts to establish elasticity coefficient between carbon emissions and energy consumption. The coefficient can clearly show the sensitivity of carbon emissions on energy consumption. The model of carbon emissions--energy consumption elasticity coefficient is as follows:

$$
e^{c e}=\frac{\Delta c / c}{\Delta e / e}=\frac{\Delta c}{\Delta e} \cdot \frac{e}{c}
$$

$e^{c e}$ is the carbon emissions--energy consumption elasticity coefficient. $C$ is the carbon emissions. $e$ is the energy consumption.

\section{B. DC-MSV model}

In this paper, the main work is studying the time-varying correlation between carbon emissions and energy consumption. So we uses multivariate stochastic volatility model to do the research. In order to estimate the timevarying correlation coefficient, we select the dynamic correlation multivariate stochastic volatility model (DCMSV model). The model is as follows:

Suppose $y_{t}$ is the logarithmic growth rate at time t.

$$
\begin{aligned}
& \quad \mathbf{y}_{\mathbf{t}}=\left(y_{1, t}, y_{2, t}\right)^{\prime}, t=1,2,3 \ldots T ; \boldsymbol{\varepsilon}_{\mathbf{t}}=\left(\varepsilon_{1, t}, \varepsilon_{2, t}\right)^{\prime} ; \\
& \boldsymbol{\eta}_{\mathbf{t}}=\left(\eta_{1, t}, \eta_{2, t}\right)^{\prime} ; \\
& \mathbf{u}=\left(u_{1, t}, u_{2, t}\right)^{\prime} ; \mathbf{h}_{\mathbf{t}}=\left(h_{1, t}, h_{2, t}\right)^{\prime} ; \\
& \mathbf{\Omega}_{\mathbf{t}}=\operatorname{diag}\left(\sigma_{t}\right) ;
\end{aligned}
$$




$$
\begin{gathered}
\phi=\left(\begin{array}{ll}
\phi_{11} & \phi_{12} \\
\phi_{21} & \phi_{22}
\end{array}\right) \quad ; \quad \sum_{\varepsilon}=\left(\begin{array}{cc}
1 & \rho_{\varepsilon} \\
\rho_{\varepsilon} & 1
\end{array}\right) \\
\sum_{\boldsymbol{\eta}}=\left(\begin{array}{cc}
\sigma_{\eta 1}^{2} & \rho_{\eta} \sigma_{\eta 1} \sigma_{\eta 2} \\
\rho_{\eta} \sigma_{\eta 1} \sigma_{\eta 2} & \sigma_{\eta 2}^{2}
\end{array}\right) \\
\text { DC-MSV can be expressed as: } \\
\mathbf{y}_{\mathbf{t}}=\boldsymbol{\Omega}_{\mathbf{t}} \boldsymbol{\varepsilon}_{\mathbf{t}} \quad \boldsymbol{\varepsilon}_{\mathbf{t}} \sim \mathbf{N}\left(\mathbf{0}, \sum_{\varepsilon, \mathbf{t}}\right) \\
\sum_{\varepsilon, \mathbf{t}}=\left(\begin{array}{cc}
1 & \rho_{\varepsilon, t} \\
\rho_{\varepsilon, t} & 1
\end{array}\right) \\
\mathbf{h}_{\mathbf{t}+\mathbf{1}}=\boldsymbol{\mu}+\operatorname{diag}\left(\phi_{11}, \phi_{22}\right)\left(\mathbf{h}_{\mathbf{t}}-\boldsymbol{\mu}\right)+\boldsymbol{\eta}_{\mathbf{t}} \\
\boldsymbol{\eta}_{\mathbf{t}} \sim \mathbf{N}\left(\mathbf{0}, \operatorname{diag}\left(\boldsymbol{\sigma}_{\boldsymbol{\eta} 1}^{2}, \boldsymbol{\sigma}_{\boldsymbol{\eta} 2}^{2}\right)\right) \\
q_{t+1}=\psi_{0}+\psi\left(q_{t}-\psi_{0}\right)+\sigma_{\rho} v_{t} v_{t} \sim N(0,1) \\
\rho_{t}=\frac{\exp \left(q_{t}\right)-1}{\exp \left(q_{t}\right)+1}
\end{gathered}
$$

Formula (2) is the logarithmic growth rate equation of the sample, $\mathbf{y}_{\mathbf{t}}$ are the logarithmic growth rate from $\mathrm{t}-1$ to $\mathrm{t}$ moments. $\boldsymbol{\Omega}_{\mathbf{t}}, \mathbf{h}_{\mathbf{t}}$ are the two-dimensional standard deviation vector. $\boldsymbol{\varepsilon}_{\mathrm{t}}$ Obey the two-dimensional multivariate normal distribution. Its mean value is $0 . \sum_{\varepsilon, t}$ is the covariance matrix. $\rho_{\varepsilon}$ is the correlation coefficient.

Formula (3) is the volatility equation. $\boldsymbol{\mu}$ is $2 \times 1$ dimensional parameter vector. $\phi_{11} 、 \phi_{22}$ are parameters. $\boldsymbol{\eta}_{\mathbf{t}}$ is normal distribution which mean is 0 and

\begin{tabular}{|c|c|c|c|}
\hline series & $\begin{array}{c}\mathrm{t}- \\
\text { value }\end{array}$ & $\begin{array}{c}\mathrm{P}- \\
\text { value }\end{array}$ & conclusion \\
\hline carbon emissions & 1.026 & 0.99 & $\begin{array}{c}\text { non- } \\
\text { stationary }\end{array}$ \\
\hline Log of carbon emissions & -0.27 & 0.92 & $\begin{array}{c}\text { non- } \\
\text { stationary }\end{array}$ \\
\hline $\begin{array}{c}\text { Log growth rate of carbon } \\
\text { emissions }\end{array}$ & -3.14 & 0.03 & stationary \\
\hline Energy consumption & 0.32 & 0.97 & non- \\
\hline
\end{tabular}
variance is $\operatorname{diag}\left(\sigma_{\eta 1}^{2}, \sigma_{\eta 2}^{2}\right) \cdot \sigma_{\eta 1}^{2} 、 \sigma_{\eta 2}^{2}$ are the parameters.

\section{THE EMPIRICAL RESULTS}

\section{A. Stationary test of carbon emissions and energy} consumption time series

In this paper, we use the ADF method to do the stationary analysis, The result is shown in table 1.

TABLE I. Stationary test of the time series

\begin{tabular}{cccc}
\hline Log of energy consumption & -0.16 & 0.93 & $\begin{array}{c}\text { stationary } \\
\text { non- } \\
\text { stationary } \\
\text { stationary }\end{array}$ \\
$\begin{array}{c}\text { Log growth rate of energy } \\
\text { consumption }\end{array}$ & -4.32 & 0.00 & \\
\hline
\end{tabular}

From the results in table 1, we can see that the data of carbon emission and energy consumption themselves and their logs are the non-stationary time series. The logarithmic growth rate of carbon emission and energy consumption are stationary time series.

\section{B. Regression between carbon emissions and energy consumption}

We firstly determine the linear relationship between carbon emission and energy consumption by using the linear regression, the regression results are shown in table 2 .

TABLE II. REGRESSION RESULTS BETWEEN CARBON EMISSION AND ENERGY CONSUMPTION

\begin{tabular}{cccc}
\hline $\begin{array}{c}\text { Dependent } \\
\text { Variable }\end{array}$ & constant & $\begin{array}{c}\text { Log growth rate of } \\
\text { energy } \\
\text { consumption }\end{array}$ & adj. $R^{2}$ \\
\hline $\begin{array}{c}\text { Log growth rate } \\
\text { of carbon } \\
\text { emissions }\end{array}$ & 0.01 & $0.68^{* *}$ & 0.20 \\
\hline
\end{tabular}

Note: $* *$ is the significance level of $5 \%$

We can see that there is a clear positive relationship between carbon emissions and energy consumption. The slope of the regression is 0.68 and is significantly different from 0 at the $5 \%$ significance level. This means that when the energy consumption growth rate changes 1 units, the carbon emissions will change 0.68 units. The results of this regression shows that there is a strong positive correlation between the carbon emissions and energy consumption. So we need to further investigate the dynamic relationship between them.

\section{Carbon emissions--energy consumption elasticity coefficient}

In this part we want to know how much carbon emission changes caused by the 1 unit change of energy consumption. The elasticity coefficient between energy consumption and carbon emissions is needed. We extract anal carbon emissions--energy consumption elasticity coefficient according to equation (1). The results are shown in figure 1. 


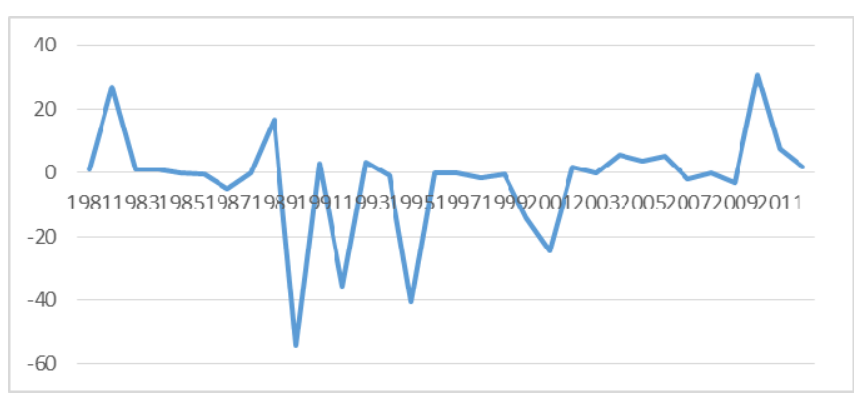

Figure 1. Carbon emissions--energy consumption elastic coefficient

Figure 1. Shows the elasticity coefficient between carbon emissions and energy consumption. From the figure we can see that the elasticity changes drastically. The relatively large fluctuations arouse our interest of predicting carbon emissions--energy consumption elasticity coefficient. When we are able to find an index which can reasonably predict the elasticity, we can accurately predict the carbon emissions of the next year. According to the national macrocontrol, we can get a glimpse of the future national energy consumption for the next year. According to the carbon emissions--energy consumption elasticity coefficient, we can preliminary estimate the carbon emissions of the next year. The prediction result can be very effective in controlling the future carbon emissions, and is vital important for saving energy and making energy strategy. In the following section we use the dynamic correlation coefficient to predict the elasticity.

\section{The correlation between carbon emissions and energy consumption}

The main contents of this section is further studying the time-varying correlation between carbon emissions and energy consumption. We use the dynamic correlation multivariate stochastic volatility model to do the research.

In this paper we select the Gibbs sampling method to estimate the parameters. We found that DC-MSV model has following parameters: $u_{c} 、 u_{g} 、 \phi_{c c} 、 \phi_{g g} 、 \sigma_{\eta c}$ 、 $\sigma_{\eta g} 、 \psi_{0} 、 \psi 、 \sigma_{\rho}$. Parameter estimation results as shown in the following table.

TABLE IV. ESTIMATION RESULTS OF THE DC-MSV MODEL

\begin{tabular}{cccccccc}
\hline Para & mean & S.D. & $\begin{array}{c}\text { MC } \\
\text { error }\end{array}$ & Para & mean & S.D. & $\begin{array}{c}\text { MC } \\
\text { error }\end{array}$ \\
\hline$u_{c}$ & -5.27 & 0.32 & 0.016 & $\sigma_{\eta e}$ & 94.75 & 61.58 & 1.96 \\
$u_{e}$ & -5.36 & 0.31 & 0.016 & $\psi_{0}$ & 1.83 & 0.37 & 0.02 \\
$\phi_{c c}$ & 0.86 & 0.10 & 0.002 & $\psi$ & 0.86 & 0.11 & 0.002 \\
$\phi_{e e}$ & 0.85 & 0.11 & 0.002 & $\sigma_{\rho}$ & 95.39 & 61.94 & 2.12 \\
$\sigma_{\eta c}$ & 94.95 & 60.57 & 1.97 & & & & \\
\hline
\end{tabular}

Using the above estimation results, we can get the dynamic correlation coefficient between the logarithmic growth rate of carbon emissions and energy consumption. The result is shown in Figure 2.

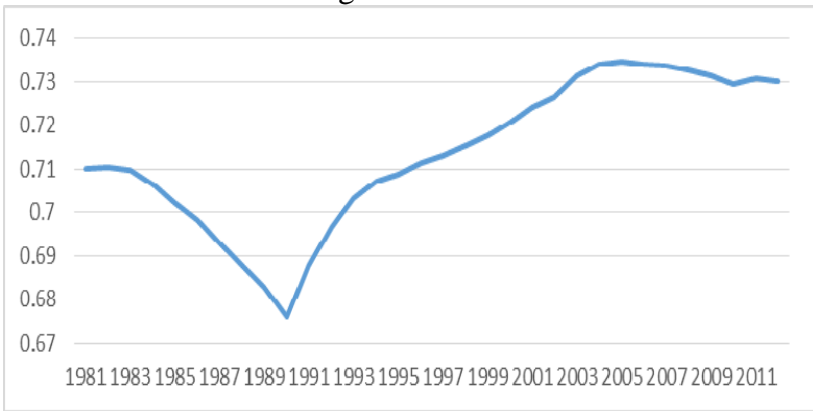

Figure 2. The correlation between the carbon emission and energy consumption

As you can see from figure 2:

First of all, there is a very strong correlation between Chinese carbon emissions and energy consumption. From 1981 to 2012, the correlation coefficients are above 67\%. This shows that there is a strong positive relationship between carbon emissions and energy consumption in China. It further says that in order to reduce carbon emissions, we must reduce energy consumption by increasing the utilization of resources.

Secondly, from the correlation coefficient after 2005 we can see the correlation coefficient between carbon emissions and energy consumption slowly decreased. It has great significance for Chinese environment development. This shows that our country has begun to pay attention to the relationship between energy consumption and carbon emissions, and looked for the positive method to reduce the impact of the increasing energy consumption on the carbon emissions.

\section{E. The predictive ability of the correlation coefficient.}

From Figure 2 we can see that the correlation coefficient between carbon emissions and energy consumption has strong time variant property. We naturally want to know the information about the coefficient correlation. Whether it has predict power on the carbon emissions--energy consumption elasticity coefficient. So in this segment, we use the regression analysis method to study the prediction ability. Mainly use the time-varying correlation coefficient to predict the carbon emissions--energy consumption elasticity coefficient. The regression results as shown in table 5:

TABLE V. THE PREDICTION ABILITY OF THE TIME-VARYING CORRELATION COEFFICIENT

\begin{tabular}{ccccc}
\hline Model & constant & $\begin{array}{c}1 \text { period lag of } \\
\text { elasticity }\end{array}$ & $\begin{array}{c}\text { correlation } \\
\text { coefficient }\end{array}$ & adj. $R^{2}$ \\
\hline $\begin{array}{c}\text { Model } \\
1\end{array}$ & -2.67 & -0.10 & & -0.02 \\
$\begin{array}{c}\text { Model } \\
2\end{array}$ & - & & & \\
\hline
\end{tabular}

Note: $* * *$ is the significance level of $1 \%$ 
Table 5 respectively report the forecast ability of the 1 period lag of the elasticity and the correlation coefficient. The conclusion show that the time-varying correlation coefficient has a certain predictive ability on the carbon emissions-- energy consumption elasticity coefficient:

Firstly, comparing two prediction models, from model 1 wen can see that the AR(1) model has no prediction ability on carbon emissions -- energy consumption elasticity. From model 2 we can see that the time-varying correlation coefficient has a certain predictive ability on the future elasticity coefficient between carbon emissions and energy consumption.

Secondly, from the view of regression coefficient, the slope of regression is 333.76. This means that when the correlation coefficient rises, the Chinese carbon emissions-energy consumption elasticity coefficient will rise. This conclusion is consistent with the actual situation. The result of this regression shows that, when the correlation coefficient rises, it indicates that there is a more closely relationship between energy consumption and carbon emissions, one unit change of energy consumption causes a large change in carbon emissions, thus increases the elasticity coefficient between carbon emissions and energy consumption.

\section{CONCLUSIONS}

According to the research results of this paper, we give the following policy recommendations:

First of all, developing the clean energy. From the results of this study, in order to reduce carbon emissions, reducing energy consumption is the key factor. Therefore, the development of clean energy is the optimal choice, such as nuclear energy, wind energy, tidal energy etc.

Secondly, improving the using efficiency of energy. From the results of this paper we can see that improving energy efficiency is another way to reduce carbon emissions. When the energy utilization rate is improved, the absolute amount of energy demand will inevitably reduce, carbon emissions are reduced.

Thirdly, developing the circular economy. The development of the circular economy is an important choice to reduce carbon emissions. Promoting the circular economy is conducive to reducing the exploitation of resources.

\section{REFERENCES}

[1] Hocaoglu F O, Karanfil F. Examining the link between carbon dioxide emissions and the share of industry in GDP: Modelling and testing for the G-7 countries. Energy Policy, 39(6), pp.3612-3620, 2011.

[2] Peters G P, Marland G, Le Quéré C, et al. Rapid growth in CO2 emissions after the 2008-2009 global financial crisis. Nature Climate Change, 2(1), pp.2-4, 2012.

[3] Selden T M, Song D. Environmental quality and development: is there a Kuznets curve for air pollution emissions? Journal of Environmental Economics and management, 27(2), pp. 147-162, 1994.

[4] Wang P, Dai H, Ren S, et al. Achieving Copenhagen target through carbon emission trading: Economic impacts assessment in Guangdong Province of China. Energy, 2014.

[5] Yu S, Wei Y M, Wang K. Provincial allocation of carbon emission reduction targets in China: an approach based on improved fuzzy cluster and Shapley value decomposition. Energy Policy, 66, pp.630644, 2014.

[6] Zhang Y, Zhang J, Yang Z, et al. Regional differences in the factors that influence China's energy-related carbon emissions, and potential mitigation strategies[J]. Energy Policy, 39(12), pp. 7712-7718, 2011. 